\title{
RACE, SPACE, AND BICYCLE PEDAGOGY
}

\author{
Grace I. Yeh \\ California Polytechnic State University
}

In my teaching about race in the United States, one of the challenges I encounter is connecting the history of race and racism to the present moment and to the realities that students experience in our so-called post-racial moment. In the classes in which I fail to make the connection clear, students claim that race no longer matters, that there is really no longer such a thing as institutionalized racism or structural injustice along racial lines, that the only form of racism we consistently see is stereotyping, which will lose its power if you just ignore it or not let it bother you. As a teacher, I am always asking: How can I create for students a more intimate understanding of our multiethnic history by having them explore the continuing relevance of these histories in our present and immediate social landscape? How can we not only nostalgically celebrate the contributions of America's diverse peoples but also recognize and engage with the lasting legacy of race and racism in the United States?

During a recent fall quarter, a colleague in the Ethnic Studies Department at California Polytechnic State University, San Luis Obispo, and I each taught one section of a lower-division general education course titled "The Global Origins of U.S. Cultures." According to the university course catalog, this course examines "how the global dispersal of Europeans, Asians, and Africans, the hemispheric dispersal of Latin Americans, and the forced internal migration of Native Americans have contributed to American cultural heritage and the struggles for ethnic, class and gender equality, and justice." To address the challenges I just described, we decided to organize our course by having students create a public bicycle tour of multiethnic historical sites around San Luis Obispo-perhaps all the more eye-opening because the community and the university are not known for their racial and ethnic diversity. We asked students to explain the region's demographics (which happen to be not only whiter than California but also whiter than even the United States as a whole), to find out about the diverse but under-documented communities that helped to define the region, and to relate these findings not just to abstract racial attitudes but to material and structural developments that enabled the movement, displacement, or settlement of communities.

At the end of the fall quarter, on a beautiful day in December with about seventy riders and walkers, students presented their research and analysis during a tour of eight sites around downtown San Luis Obispo. Perhaps any public presentation of student research would succeed in increasing student investment in the course content and

\footnotetext{
'I would like to acknowledge Yolanda Tiscareño, Don Ryujin, Victor Valle, Joy Harkins, Dan Rivoire, Kimberly Timbs, Catherine Trujillo, and the Fall 2010 ES212 students at Cal Poly for their efforts to support the course and make its final tour project a success. Most of all, I thank Denise Isom, my indispensable collaborator.
} 
assignments. Apart from this particular advantage of a community-based learning project, I believe other aspects of our bicycle tour project also increased student interest and helped bring to life the dusty archive.

The tour and the course made the relevance of race and racial formation more concrete, specifically by examining racial formation through what I called "technologies of mobility," meaning mechanisms (structural or conceptual) that organized and disciplined bodies in the production of power (e.g., state power). These technologies include transportation technologies such as the bicycle, the steam engine, railroads, jet engines, the car, pavement, highway systems, and pneumatic tires; they also include governmental or organizational technologies such as road rules, rules about the use of public space, immigration legislation, city planning, zoning, home loan policies, and property ownership laws. These technologies not only produce movement and lay out spaces in the landscape; they also produce social identities-including racialized identities - and mediate relationships of power among social players. Thus, the bicycle-a practical and pleasant way to reach our tour stops downtown-worked double-duty as a conceptual and pedagogical tool: It helped students and tour participants engage with how social identities, space, and power emerge in relation to very concrete, even ordinary, instruments that govern human physical and social mobility.

In what follows, I provide a pragmatic guide to helping students create and host a public bicycle tour of the multicultural history of San Luis Obispo. I also include an overview of the course content and analytical framework, which will explain the theoretical significance of the bicycle tour. The bicycle history tour, as a communitybased learning project, proved to be a rewarding and effective way to have general education students pursue archival research, communicate their research and argument clearly, and examine critically the intersections of mobility, race, and historical memory in their immediate and contemporary social landscape. Granting that our course was place-specific (keyed to San Luis Obispo), I believe that this sort of course design could be replicated at colleges and universities in diverse sites across the country.

\section{Bike as Theory}

So, why the bicycle? The idea came to me as I reflected upon my own experiences living in Los Angeles without a car and during the bus strikes - this taught me quite a bit about the politics, culture, and history of mobility. One cannot help but to notice the race and class stratifications mirrored through the city's transportation routes and planned spaces. It occurred to me that the bicycle offered students a productive analogy for understanding the relationship between mobility and power. Bicycle movements of the last few decades-and from a century ago--offer invaluable lessons on socially constructed geographies. My inspirations for a student-hosted bicycle tour were the bike events in automobile-dominated Los Angeles, including Midnight Ridazz, Critical Mass, and CicLAvia. These grassroots "movements about 
movement" engage in playful and creative contestations of infrastructure and rules about how to use the road. Bicycle advocacy groups are also attuned to the impact of governmental acts and subsidies and of local political action on our built environment. The bicycle allowed us to consider a transportation mode that had become marginalized since the introduction of Ford's automobile. What most of us do not know is that in the nineteenth century cyclists—or "wheelmen," as they were called—had once enjoyed some amount of political and social clout. Given the costs of the first safety bicycles, cyclists belonged to a leisure class with access to the political sphere. They even facilitated the transition from the horse to the automobile by lobbying for paved roads. ${ }^{2}$ Thus, the contingencies of the bicycle's status gave us a perch from which to gaze critically upon the production of power, space, and social identities via the dominant structures governing the movement of peoples.

Another compelling case study for this relationship between technology, mobility, and social power is the bicycle's starring role in the fin-de-siècle women's movement. The first bicycles not only created more accessible public and recreational spaces (e.g., by creating paved routes and collapsing distances), but, by increasing access in this way, they also helped change women's position in society. As noted in the magazine Puck in 1892, "Perhaps the time when a woman most feels that she is the full equal of any man is when she has begun to feel at home on a bicycle." The bicycle, in other words, no longer confined "home" to the domestic sphere but made women at home in the public sphere as well. In addition to healthy exercise, the bicycle offered women freedom of movement, even unchaperoned forays into public spaces. It catalyzed dress reform as women cyclists shed restrictive Victorian dress for bloomers and clothing seen by some as "too masculine." Leading figures in the early women's movement reiterated this intimate link between gender equity and the bicycle. In her 1898 letter to the editor of Sidepath magazine, Susan B. Anthony claimed that "the bicycle preaches the necessity for woman suffrage." Given the numbers of bicycle

\footnotetext{
${ }^{2}$ Two particularly useful bicycle histories are Robert A. Smith, A Social History of the Bicycle: Its Early Life and Times in America (New York: American Heritage Press, 1972), and David V. Herlihy, Bicycle: The History (New Haven: Yale University Press, 2006). Jeff Mapes, Pedaling Revolution: How Cyclists are Changing American Cities (Corvallis: Oregon State University, 2009), helps relate this past history to current grassroots bike movements.

3“"An Early Bird," Puck, September 7, 1892.
}

${ }^{4}$ Sue Macy, Wheels of Change: How Women Rode the Bicycle to Freedom (with a Fèw Flat Tires along the Way) (Washington, DC: National Geographic Society, 2011), 70, 74. 
enthusiasts among women, Anthony argued that wheelmen, lobbying for bike-friendly legislation, also should advocate for full suffrage for women. ${ }^{5}$

Rather than upholding the bicycle as a democratic instrument or "the great leveler," as some have done ${ }^{6}$ I wanted students instead to understand that technologies as seemingly innocent or mundane as a bicycle are not innocent of power, and in fact have the power to radically transform geography, social position, and identity. In using the bicycle as theory, I was asking students to critique the structures of power that establish our various forms of physical and social mobility. For the purpose of our project, other modes of transportation certainly could have worked well- the key is to historicize the links between technology, the politics of mobility, and social geography. We live amidst "geographies of privilege and power," as urban planning scholar Edward Soja explains, and although these geographies create "lasting structures of unevenly distributed advantage and disadvantage," they "can be changed through forms of social and political action." "The public bicycle tour offered one form of action to begin questioning our local social and political geographies.

\section{Assignment}

The tour assignment asked students to synthesize what they learned about race and mobility with an analysis of historical memory. It was premised on a simple claim: A town, as both an imagined community and a geographic site, emerges out of both its infrastructural and its discursive constructions. In other words, a town's sense of itself as a community depends as much upon its histories - the documentation of and narratives told about it —as on the structured migrations, settlements, and displacements

\footnotetext{
${ }^{5}$ While many bicycle histories address the technology's impact on women, very few address race. This absence is notable as the historic U.S. Supreme Court case, Plessy v. Ferguson (1896), which upheld segregation laws under the doctrine "separate but equal," was decided in the midst of the nineteenthcentury bicycle craze, and the bike boom in the early 1970s happened, as Mapes points out, "in an America that was becoming accustomed to revolutionary change- think of women's liberation, racial equality, the anti-war movement, gay rights, and R-rated movies" (in Pedaling Revolution, 24). A few histories, including biographies of Marshall "Major" Taylor, the record-holding cyclist and one of the first black star athletes in the U.S., note how segregation extended to bicycle organizations and events (Herlihy, 263; Smith, 162-4). One notable exception is Dan Koeppel's "L.A.'s Invisible Riders," a rare look at immigrant day laborers, a cycling constituency mostly overlooked by bicycle advocacy groups (reprinted in Utne, July/August 2006. http://www.utne.com/2006-07-01/LnvisibleRiders.aspx (accessed September 11, 2014). See also Los Angeles-based City of Lights program, which outreaches to minority cyclists.
}

${ }^{6}$ Smith cites a few publications of the time that claim the bicycle as an instrument of democracy, as "the great leveler," especially in contrast to the hierarchy of other transportation modes, horse drawn carriages for the well-to-do and cable cars for the lower classes (Smith, 112).

${ }^{7}$ Edward Soja, Seeking Spatial Justice (Minneapolis: University of Minnesota Press, 2010), 20. 
these histories describe. In particular, we considered these representational and structural developments as a "racial project," which Michael Omi and Howard Winant define as "simultaneously an interpretation, representation, or explanation of racial dynamics, and an effort to reorganize and redistribute resources along particular racial lines."

Since we had two sections of students, we decided to run two concurrent tours but starting at different points along the route. We each had about 35 students, whom we divided into groups, with each group assigned a tour point to research as a local case study. Based on their research, they were then to produce a script to present at their point along the bicycle tour. Dubbed by the students "Tour de SLO: A Path Through Our Multi-Ethnic History," the free public tour covered eight historic sites, selected by the instructors before the start of the term (see below for more explanation), that reflected the politics of space and movement:

(1) the railroad station, where students presented research on immigrant labor and the geographical and social changes wrought by this technology;

(2) the Dallidet Adobe built by a French immigrant who married into a prominent Mexican family, part of the power shift enacted both in national and intimate spheres following the Mexican-American War;

(3) a store and street that was the center of a nineteenth-century German-Jewish immigrant community, which exemplified the adaptation and assimilation of a European ethnic group;

(4) Chinatown and the analysis of class in the local white community's embrace of its most prominent Chinese merchant;

(5) Mission de la Tolosa, focusing on the culture of the Chumash, including their shipbuilding and navigation skills, and the erasure of indigenous culture and history subsequent to the arrival of Spanish missionaries;

(6) Murray Adobe, home of prominent citizen Walter Murray who led the Vigilance Committee as political power and land were transferred from Mexicans to Americans;

(7) Japantown, its pre-war community, and the impact of internment

(8) Brook Street, an African-American neighborhood formed in the vacuum created by the internment of Japanese-Americans and the seat of a local civil rights movement.

The students were not only tasked with uncovering for themselves hidden histories and thereby bearing witness to an often unmarked presence in the landscape; they also were

${ }^{8}$ Michael Omi and Howard Winant, Racial Formation in the United States: From the 1960s to the 1990s, second ed. (New York: Routledge, 1994), 56. 
challenged to understand the material conditions that brought diverse groups to the region but allowed only a few to stay.

We required every student, through participation in one of the groups, to conduct research and produce a tour script for one tour point as a part of the course requirements; however, participation in the ride was not required, as some students were not comfortable biking or had other commitments on tour date. Students who decided to participate in the tour-either as tour guides, ride leaders, or in public relations - received twelve service learning hours. For those who did not participate in the tour, service learning hours could be fulfilled through volunteering opportunities with the SLO Bicycle Coalition, such as in their bike kitchen or with their bike valet programs, or at the History Center of San Luis Obispo County by serving as docents or research assistants. The intention of these particular volunteering opportunities was to introduce students to community resources that illustrate the effect infrastructure and advocacy can make on the local culture. ${ }^{9}$

To prepare the scripts for the assigned tour point, each student group was required to produce an annotated bibliography, which had to include sources from local archives. Students were encouraged to contact local community members for their research. For example, one group visited a Chumash elder and the culture center he cofounded with his wife. The groups then had to present to the class their research findings, as well as provide a larger historical context for the archival materials they found. Students were to evaluate what was and was not represented or well documented. These presentations also provided student groups an opportunity to receive feedback from peers on which of their research findings seemed relevant and interesting to share with the public. Finally, each group produced a fifteen-minute tour script based upon their research findings. We encouraged student groups to include personal or even alternative perspectives and to give voice to the community represented, for example, by including passages from family letters or oral history interviews that they found in the archives.

\section{Course Content and Project Scaffolding}

The course content provided students with larger historical, cultural, and critical contexts to analyze primary materials (or lack of materials) from the local archives. To introduce students to the project and to the course - and to the relationship between the construction of historical narratives, the construction of social geography, and racial formation-I conducted an in-class exercise in which I asked students to generate a list of questions relating to race and race relations that remain unanswered in the city's brief

\footnotetext{
${ }^{9}$ The University's Community Center supports faculty with service learning courses and has experience placing student volunteers in the community.
} 
history of itself provided on its website. ${ }^{10}$ At first glance, students noted how the history acknowledges, rather than overlooks, the place of Chumash and Salinan Indians, Spaniards, Mexicans, Anglo-Americans, Chinese, and Japanese in the town's past. Given the town's demographics, the town's multiethnic history is not only surprising but reassuring to learn since students were able to see that the town acknowledges the contributions of a diverse group of peoples and cultures, even if they are largely no longer present.

Once students began generating a list of unanswered questions, they were able to look beyond representational diversity and start to examine critically this diversity in relation to power. Students, for example, were quick to note the elisions in the section describing first Western contact, asking, "Why don"t they mention the interaction between Native Americans and Spanish?" Thus, they recognized how the narrative fails to go beyond identifying diverse populations to take into account the struggles and conflicts among groups along racial or ethnic lines. Students also often asked for further elaboration on communities that were once here-e.g. the Chinese and the Japanese. I put this list of questions on the course website so that students could refer back to it as research questions when they began researching and writing their own narratives for the bicycle tour.

The brief history also offered an opportunity to introduce the structured settlements or displacement of different communities and how these movements are depicted. For example, we asked: Why did "families such as the Picos and the Estradas [sell] much of their land to Anglo newcomers, including the Steele brothers, George Hearst, and Patrick Murphy"? Why were Chinese recruited to work on the local rail? Why were few Japanese farmers "able to own land, and only a small number returned to the County after the end of the war"? ${ }^{11}$ And how did the conditions for settlement or displacement of communities affect how they were regarded or racialized?

To understand the answers to these questions relating to mobility and race, course units on the various cultures and communities were examined in relation to different technologies of mobility. For example, we covered U.S. immigration history, including the legislation regulating the racial and class composition of the U.S. and the legal and economic formation of the "back door." We studied the construction of whiteness and United States geography through Indian removal, dispossession of Mexican lands, and policies informed by the ideology of Manifest Destiny. We looked at slavery, segregation in the Jim Crow era, and then post-World War II suburbanization or "white flight," where the formation of the urban ghetto was underwritten by the development of the interstate highway system along with government-backed housing subsidies, the

${ }^{10}$ City of San Luis Obispo, "A Little More History," http://www.slocity.org/history.asp (accessed September 11, 2014).

${ }^{11}$ Ibid. 
phenomenon of "red-lining" and racist housing covenants. ${ }^{12}$ These policies resulted in an America that is even more segregated today than in the pre-Civil Rights era. ${ }^{13} \mathrm{We}$ also looked at the mobilizations of World War II, from the movement of AfricanAmericans to the city and to the West, to Japanese-American internment (euphemistically called "relocation" by the federal government), and to the reversal of immigration exclusions from Asia during the Cold War.

We also focused on counter-movements that challenged the governance of movement and space. For example, we looked at the history and the political and cultural significance of Chicano lowriders. Cultural historian Denise Sandoval explains the emergence of Chicano lowriders after the Second World War when working class Chicanos, with technical skills gleaned from military service, co-opted surplus military technology and cast-off automobile parts to build customized automobiles. As in the largely Anglo-American hot-rod culture, lowriders refused the homogeneity of factorymade cars and postwar suburbia but with a Chicano aesthetic and an emphasis not on speed but on display. Ben Chappell's work focuses on what he calls "spatial governmentality," the way that space and the racialization of that space is policed. $\mathrm{He}$ looks at how lowriders and cruising in the American Southwest transgress these racialized spaces, bringing the barrio to the main street. ${ }^{14}$ Counter-movements also included cultural acts that emerged out of creatively contested spatial injustices. We covered the literature of borderland communities. We studied the formation of immigrant enclaves such as Chinatowns or Little Saigon in Westminster. Finally, we ended the course with a unit on the movements against environmental racism. Majora Carter's TED lecture on greening the ghetto is short but provokes discussion, and it works well with the documentary The Garden (2008) on the South Central Farmers' fight to maintain the largest urban community garden..$^{15}$

\footnotetext{
${ }^{12}$ See Douglass S. Massey and Nancy A. Denton's chapter, "The Construction of the Ghetto," in American Apartheid (Cambridge: Harvard University Press, 1993), 17-59.

${ }^{13}$ Following historian and cartographer Bill Rankin's map of Chicago by race (see

http://www.radicalcartography.net/), programmer and designer Eric Fischer created a Flickr photostream of similar maps of U.S. cities using 2000 U.S. census data. He has since created a new set of images updated with 2010 census data. See http:/www.flickr.com/photos/walkingsf/sets/72157626354149574/ with/5559914315/.
}

\footnotetext{
${ }^{14}$ Ben Chappell, "Custom Contestations: Lowriders and Urban Space," in City \& Society, 22:1 (2010), 25-47. In the future, I would also like to include an exanination of Asian American youth import car culture. For example, See Soo Alh Kwon's "Autoexoticizing: Asian American Youth and the Import Car Scene" in Journal of Asian American Studies, 7:2 (2004), 1-26.
}

${ }^{15}$ Majora Carter's 19 minute TED lecture, "Greening the Ghetto," was filmed February 2006.

http://www.ted.com/talks/majora_carter_s_tale_of_urban_renewal.html (accessed September 11, 2014). 


\section{Pre-Term Preparations}

To execute this kind of community-based learning project, my colleague and I had a number of tasks before the term began. The first was to find the tour points for students to research since, in a ten-week course, students would not have enough time to pursue the needed research and writing and organize the tour event on top of having to worry about trying to discover the "hidden" histories of the town's ethnic communities. One consideration in selecting the tour points, especially of underdocumented communities, was to make sure that students could still find enough research materials to craft a fifteen-minute presentation as well as to articulate the link between mobility and race.

I consulted with the university's Special Collections Department and the county historical society, where the staff and volunteers, with deep knowledge of their collections, were more than willing to offer ideas for topics and communities to research. I was also fortunate that during my search there was a series of railroad events where I met railroad history buffs who could provide long lists of publications and archival sources. While most people could talk about either ethnic communities or transportation history, very few could talk about them together. Though the depth of student archival research would be limited by the term's brevity, we could push students to apply to their research findings the recent scholarship and critical frameworks that bring together ethnic studies and transportation history. ${ }^{16}$

The second major task was to learn how to organize a safe group ride. A number of recent publications on the politics and social history of the bicycle point out a recent shift from regarding bicycling as a sport or recreation to seeing it as a utilitarian form of transportation. ${ }^{17}$ Because our society does not usually see the bicycle as a commuter vehicle, there is a general lack of knowledge on the part of both automobile drivers and cyclists on how to integrate cycling into automobile traffic. The local bicycle coalition was an enormous asset in advising how to bike "smart" and how to lead and organize group rides. Before the term began, my colleague and I took a hands-on "street smarts" course, which taught us about road rules and about "vehicular cycling"- -biking on the road with cars as a vehicle. After the quarter started, we solicited eight students from each tour group to complete the street smarts course and to then serve as "ride leaders" for the tour. Their job was to guide riders during the tour as well as to advise riders of the safest way to bike from one tour point to the next. Also, the bicycle coalition

\footnotetext{
${ }^{16}$ See especially historian Cotten Seiler's intervention in transport history, "The Significance of Race to Transport History," Journal of Transport History, 28:2 (2007).

${ }^{17}$ For example, see J. Harry Wray's comparative study of bicycle cultures, Pedal Power: The Quiet Rise of the Bicycle in American Public Life (Boulder, CO: Paradigm Publishers, 2008), or Mapes, Pedaling Revolution.
} 
helped us design a route that would be easiest to negotiate on a bicycle, as well as pointing out where and how to cross lanes.

The last major task I should mention was assuring university administrators that potential liability was minimized by obtaining event insurance--it was the one task that I had the most difficulty negotiating. Because a bicycle tour would bring students out into the community, I had to go through the dean's office and the university's risk management office. Risk management stated that the college would assume any liability (but with a high deductible), and thus the dean's office required that I obtain event insurance in order to run the event. However, finding appropriate insurance coverage was a challenge--the risk associated with a group bicycle ride is quite low, but some of the insurance policies were geared toward covering liability for sports events or bicycle races, at a very high cost, and would have required us to close the route to automobile traffic. I had to reiterate that, for us, riding a bicycle as a part of the tour was a form of transportation - like walking or driving-and not a sport. The difficulty of finding an appropriate policy reiterates this dominant perception in the U.S. of bicycles as toys and cycling as a sport. However, if one is diligent, as my department's administrator was, one can find the appropriate policy, which cost us less than $\$ 200$. This issue obviously should have been settled before the term began, but it was finally resolved on a very stressful day before the event! I learned the hard way the institutional rules for how to use public spaces and how to move across institutionalized spaces - all lessons that were, it turns out, apropos to the course and tour themes of space, mobility, and power.

\section{The Tour}

Despite the forecasts of rain, the tour drew about seventy cyclists and a handful of walkers on a pleasant ride. (The rain held off, but in the future, I will not attempt a bicycle tour project during the rainy season!) From the presentations on the displacement of the local Japanese American community during the Second World War to the discussions of the sophisticated Chumash culture and science erased by Spanish colonization and the assimilation of German Jewish and Chinese merchants (versus laborers), students produced tour scripts that not only uncovered a rich history of diverse peoples that most tour participants were unaware of but they also explored the question of why historical amnesia persists. As one anonymous tour participant responded in our post-event survey, "I was so impressed with all the presentations. I particularly liked the discussions that engaged with 'dominant historical narratives' and what it means to retell history from a multicultural perspective-including asking different types of questions. I think this was particularly strong in the Chumash discussion and the Vigilance Committee."

The group covering the Vigilance Committee had organized their presentation around "the two perspectives we found when looking at the Vigilance Committee" that was formed in 1858 by Walter Murray-lawyer, eventual judge, newspaper founder, 
and all-around prominent citizen. The first perspective is the oft-circulated one "that the committee had to be formed in order to help control the violence that had plagued the area for many years and the lawlessness that the town was suffering." The alternative perspective, however, "sees that these acts may have been race-based since the vigilantes seemed to target the Californios, the Mexican citizens in California, and Native Americans." movement, in this case, not only of people but also of geopolitical boundaries. As the students state, "we have to take into consideration that the Treaty of Guadalupe Hidalgo had been signed making California now a part of the United States. The state was in transition from being Mexico to all of a sudden becoming part of the United States with different laws and procedures." Rather than claim that one is the "right" perspective, the students instead presented competing perspectives while focusing on how they are reflected by positions of power and maintenance of a new status quo. ${ }^{19}$ Instead of finding a better archive or a better interpretation, the students unsettled sedimented narratives and called attention to the reorganization and mobilization of humans along ethnic-racial lines. At least a couple of tour participants noted that the presentations "all mentioned the lack of information available to the public about the different cultures and their impact. Lack of information = lack of power."

While the tour succeeded in inviting participants to question dominant historical narratives, one thing I would change in the future is making clearer, during the tour, how technologies of mobility mediate between race, space, and power. This aim could have been achieved by assigning one student group to introduce and conclude the tour by discussing the bicycle as a tool for traversing the geographies of power constructed by various technologies of power and made evident in the narratives told at each tour point.

At least my own students took to heart the interrelatedness of spatial governmentality, constrained movements, and social identities, which was especially evident in the way they related the concepts to their own everyday experiences. For example, one student during class discussion explained the relationship between spatial governmentality and the criminalization of lowrider identities by using his experience and perceptions as a skateboarder. Another student relayed how transportation modes mark class identity, writing in his final essay: "Right now in many places, such as my home town of Napa, riding a bike for transportation is reserved solely for the poorest class. The middle class drive around huge pick-up trucks while the upper class drive luxury cars. The only time it is 'acceptable' it seems, for an upper or middle class

\footnotetext{
${ }^{18}$ Students drew from the critical framework provided in Ken Gonzalez-Day, Lynching in the West, 1850-1935 (Durham: Duke University Press, 2006).
}

\footnotetext{
${ }^{19}$ Beverley Kwang, Daisy Resendiz, Adam Fischlin, and Claudia Mendoza, "Murray Adobe," 2011. Unpublished.
} 
person to ride a bicycle is if it's on an expensive road bike on a scenic back road for exercise." Turning a critical eye toward their experiences and communities, students recognized how social distinctions and hierarchies are produced through everyday movements, and can even be reworked through mass movements and the reimagining of public spaces.

\section{Conclusion: Community-Based Learning as High Reward Learning}

A report by the Coalition for Community Schools on community-based learning notes the benefits of place-based learning, which "uses the unique history, environment, culture, and economy of a particular place to provide a context for learning. Student work is directed towards community needs and interests, and community members serve as resources and partners in every aspect of teaching and learning." ${ }^{20}$ The bike tour project takes what students see as familiar or ordinary and turns it into a setting for learning. It also extends the resources that students have available to them by drawing upon the community members and local institutions. The project also makes them accountable for what they learn because they know that they will have to produce a quality product for the local community. As the Coalition report states, in communitybased learning projects, "learning goals connect personal involvement to public purpose." 21

With this greater responsibility also comes greater satisfaction. For the students who directly participated in the tour, they felt a sense of accomplishment and relevancy in their academic work. As one student tour guide, M.H., stated, "I was pleasantly surprised to have an attentive crowd with genuine interest before me. They also participated by asking questions afterward, and I was proud when my group knew the answers. I treasure the opportunity the course provided to learn and become an expert about little-known Japantown of San Luis Obispo. Now, I enjoy telling community members about the community that once existed." Another student, E.H., also remarked on the satisfaction of producing knowledge and a new perspective on the local community: "I enjoyed learning about the city that I have resided in for the last 4 years... The most memorable part of this experience was being a part of expanding the knowledge of the local residents and students of San Luis Obispo. Watching the guests of the tour learn and ask questions about the information at each stop made me feel that I was making a difference in the understanding of our city history. I also

\footnotetext{
${ }^{20}$ Atelia Melaville, Amy C. Berg, and Martin J. Blank, "Community-Based Learning: Engaging Students for Success and Citizenship" (Washington, DC: Coalition for Community Schools, 2006), 8-9, online at http://www.communityschools.org/assets/1/AssetManager/CBL_Book_1_27_06.pdf.
}

${ }^{21}$ Ibid., 9. 
enjoyed seeing the relevance of all the hard work put in by everybody involved because without their combined effort this event would have never gotten off the ground."

Student comments also suggest the benefits of this community-based project as active and visceral learning. A.B.'s simple realization-that she "saw how easy it is to get around town on a bike"--shows that actually engaging in an act, rather than hearing about it, is much more transformative and revelatory. B.I. recognized how segregation is enabled not only by social proscriptions against whom we can share space with but also by the way our movement through social spaces is shaped by the machinery of movement. As he wrote in his essay: "When viewed from a car, interactions with the people and community in SLO [San Luis Obispo] are so limited. Your mode of transportation in a car constructs a sort of segregated social space that separates you from the rest of the community." Finally, one course evaluation comment made me realize how this kind of active leaming can be effective for teaching across disciplines or to students who might have a difficult time relating to the theory and content in humanities courses. As this student wrote, "As an engineer, I constantly wonder what I'm missing out on by focusing on a single aspect of science. This course has not only sparked my interest in learning more but gave me hope that I can." Project-based learning that uses the local setting as a concrete teaching and learning site provides an immediate, kinetic, and intimate experience for the students, which adds to the more abstract or distant histories covered in the course texts.

Learning that offers a new way of seeing is not only memorable but also satisfying for the learner. But I would argue that this kind of teaching and learning experience is all the more important when we teach about the history of race in America. Students almost always understand the injustice of the kinds of blatant racial discrimination that was socially and legally permissible in the United States before the Civil Rights Movement. The challenge in teaching about race in the purportedly "postracial" moment is connecting that historical legacy to the present moment. When asked why we need to know this history, students commonly respond, "so that we can learn from the past and not repeat it"-confining racism to "back then." But how does the present moment bear the bitter fruits of the past? Instead of a lesson in how far we have come, our multiethnic history - or any history-becomes more meaningful when it provides us a genealogy of the present moment, helping us to better trace the shape of our contemporary social landscape. 